\title{
Partisipasi Masyarakat Dalam Pengelolaan Community Based Tourism Di Desa Wisata Waturaka, Kabupaten Ende
}

Michael Rudolfus Sawu a, 1, Dian Pramita Sugiarti a, 2

1 Michaelrudolfus@gmail.com 1,dian_pramita@unud.ac.id

Program Studi S1 Destinasi Pariwisata, Fakultas Pariwisata,Universitas Udayana, Jl. Dr. R. Goris, Denpasar, Bali 80232 Indonesia

\begin{abstract}
Waturaka Tourism Village is a community-based development. Waturaka tourism village has a wealth of natural resource assets and also a very massive culture. Therefore, managing elements of tourism products through the concept of "community based tourism" is ideal in an effort to provide economic benefits for local communities, nature and cultural conservation amid the rampant negative conventional mass tourism. This study aims to look at the components of tourism planning and community participation in it to produce philosophical implementation of community-based tourism.Technique used to collect the data in this research is observation, interview as well as literature study. Descriptive qualitative is used as the data analysis technique in this research.

The results of this study indicate that, the management of the tourism product component in Waturaka tourism village was managed by community with a very high level of participation (citizen power) on one hand but not on the other. It is because the motive of local people's enthusiasm to develop community-based tourism in terms of awareness of global reality. Suggestions from this research are tourism awareness groups (Kelompok sadar wisata) are expected to build networks with external parties in the context of the tourism village marketing, the government and non-government organization is expected to continue to empower local communities so as to produce massive competence in the tourism industry in order to provide maximum satisfaction to tourists.
\end{abstract}

Keywords: CBT, Tourism village, participation.

\section{I.Pendahuluan}

Filosofi pariwisata berbasis masyarakat adalah keaktifan partisipasi masyarakat dengan tujuan untuk menghasilkan kesejahteraan masyarakat itu sendiri melalui pengembangan asset sumber daya pariwisata yang dimiliki. Pariwisata berbasis masyarakat adalah anti tesis dari pariwisata berkelanjutan sebab pariwisata berkelanjutan mengedepankan top down approach sedangkan pariwisata berbasis masyarakat mengedepankan bottom-up approach (Tasci et al,2013).

Desa Wisata Waturaka adalah bentuk implementasi suistainable tourism yang dimanifestasikan melalui pariwisata berbasis masyarakat. Pembangunan desa wisata Waturaka diinisiatifkan oleh masyarakat lokal sehingga koheren dengan filosofis pariwisata berbasis masyarakat. Desa Wisata Waturaka dikelola oleh kelompok sadar wisata sehingga teraraah pengelolaannya. Eksistensi Desa Wisata Waturaka tersebut memberikan manifestasi yang sangat signifikan dikarenakan segala aktivitas pariwisata yang berlangsung dikontrol oleh masyarakat lokal sehingga menghasilkan filosofi pariwisata berbasis masyarakat yang mampu dibaca oleh setiap kalangan dengan jelas.

Eksistensi desa wisata Waturaka telah mencapai prestasi yang sangat masif karena dijustifikasi sebagai desa wisata alam terbaik versi (Kemendes PDTT RI, 2017). Desa wisata merupakan salah satu program Kementerian Desa Pembangunan Daerah Tertinggal dan Transmigrasi RI (Kemendes PDTT RI, 2017 dalam Mahagangga, 2018).

Hal yang menjadi kasuistiknya adalah desa wisata Waturaka selalu menawarkan produk pariwisata yang dimiliki dengan basis art by destination. Estetika produk pariwisata yang dimiliki adalah karakteristik dari desa wisata tersebut yang merupakan satu kesatuan dari peradaban sebelumnya dan tetap ada sampai peradaban saat ini. Elemen tersebut menghasilkan aspek novelty yang merupakan inti sari dari pariwisata itu sendiri. Desa Wisata Waturaka dikelola oleh masyarakat lokal sehingga keterlibatan masyarakat dalam jangka pendek dan jangka panjang menciptakan prospek pengembangan desa tersebut secara efektif dan efisien. Hal ini pun sebagai anteseden pengelolaan desa wisata itu sendiri. Pengelolaan Desa Wisata Waturaka yang 
sistematis dalam perspektif pariwisata berbasis masyarakat mampu menghasilkan realitas yang pro terhadap masyrakat lokal dan juga aspek keberlanjutan. Partisipasi tersebut dalam penelitian ini digambarkan sebagai partispasi aktif dalam mengelolah sebuah desa wisata. Permasalahannya adalah masyarakat lokal Desa Wisata Waturaka belum mengoptimalkan manfaat ekonomi dari aktivitas pariwisata secara penuh.

Berdasarkan penjelasan diatas, maka dipandang perlu dibahas tentang "Partisipasi masyarakat dalam pengelolaan community based tourism di Desa Wisata Waturaka, Kabupaten Ende untuk melihat pengelolaan komponen produk pariwisata dan partisipasi masyarakat. Hal ini dilakukan untuk melihat keterlibatan masyarakat lokal sebagai aktor dan sasaran dari pengelolaan community based tourism di Desa Wisata Waturaka. Keterlibatan tersebut yang dimaksud adalah keterlibatan yang secara aktif dan pasif. Keterlibatan secara aktif artinya tersentuh langsung dengan pengelolaan desa wisata sedangkan pasif merupakan kontrasnya.

\section{Konsep dan teori}

\subsection{Konsep pariwisata berbasis masyarakat}

Konsep pariwisata berbasis masyarakat diambil dari (Hausler and Strasdas, 2003; Asker et al, 2010; UNWTO-STEP Foundation, 2011; Tasci et al, 2013) yang menekankan filosofi keaktifan dari masyarakat lokal.

Desa Wisata Waturaka dikembangkan dengan basis pariwisata community based tourism dengan melibatkan masyarakat lokal secara aktif baik dalam pengambilan keputusan jangka pendek maupun jangka panjang. Masyarakat lokal sebagai subjek dan objek dari pembangunan kepariwisataan di desa Wisata Waturaka. Masyarakat lokal sebagai subjek artinya sebagai aktor pariwisata yang mengelola destinasi pariwisata yang dimiliki sedangkan sebagai objek artinya masyarakat lokal yang menjadi sasaran dari pembangunan kepariwisatan tersebut. Pengembangan desa wisata tersebut memberi gambaran atraksi wisata dengan basis art by destination sehingga masyarakat lokal Waturaka memberi interpretasi terkait produk wisata yang dimiliki terhadap wisatawan (information satisfaction). Hal ini bisa memberikan nilai surplus yakni wisatawan juga bisa mempromosikan terhadap konservasi alam dan budaya yang dimiliki oleh masyarakat Waturaka.

\subsection{Konsep partisipasi}

Konsep yang digunakan merujuk pada Arnstein (1969) tentang kadar partisipasi yang dikemas dalam ladder of participation.

Keterlibatan masyarakat lokal Waturaka dalam pengelolaan desa wisata tersebut merupaka $\mathrm{n}$ parameter primer dalam konteks pariwisata berbasis masyarakat. Partisipasi masyarakat lokal Waturaka bila dikaji dari perspektif "ladder of participation" menghasilkan kadar partisipasi yang tinggi (citizen power) dikarenakan masyarakat lokal sangat aktif dalam pengelolaannya ditandai dengan inisiatif awal dalam pengembangan Desa Wisata Waturaka.

\subsection{Konsep desa wisata}

Konstruksi berpikir tentang desa wisata dalam penelitian ini merujuk pada Nuryanti, 1993. Hal yang ditekankan adalah link antara elemen produk pariwisata dengan the way of life yang dimiliki oleh masyarakat lokal.

Desa Wisata Waturaka merupakan desa wisata yang menawarkan atraksi yang berbasis alam dan budaya serta disajikan dengan nilainilai local genius dan didukung dengan amenitas masyarakat lokal yang digunakan untuk memenuhi kebutuhan wisatawan ketika berkunjung.

\subsection{Teori pengelolaan}

G.R. Terry menyatakan bahwa pengelolaan memiliki 4 fungsi yang sangat fundamental sebagai berikut:

1. Perencanaan

Upaya formulasi suatu pandangan strategi untuk mencapai visi dan misinya. Desa Wisata Waturaka menghasilkan formulasi strategi pengembangan dengan pendekatan pariwisata berbasis masyarakat. Strategi tersebut untuk menghasilkan dinamika pengembangan pariwisata yang berkelanjutan yang pro terhadap masyarakat lokal dari berbagai dimensi. Upaya untuk mencapai itu semua tentu membutuhkan intervensi dari pemerintah (regulator dan fasilitator) perihal kebijakan yang mengedepankan kebutuhan primer masyarakat lokal Waturaka. Desa wisata tersebut dikelolah oleh kelompok sadar wisata Waturaka untuk menjaga eksistensi alam dan budaya yang dimiliki dalam peradaban modern. Hal ini dilakukan sebagai "survival of the fittest" (Sintasan terbugar) dalam kemasan destinasi 
pariwisata untuk menjawab tesis pariwisata berkelanjutan.

2. Pengorganisasian

Tipikal determinasi, klasifikasi, dan penyusunan berbagai aktivitas yang dibutuhkan untuk mencapai tujuan. Kelompok sadar wisata Waturaka mempunyai aktivitas pertanian yang dijadikan agrowisata sebagai salah satu "nature based tourism attraction". Selain itu juga terdapat kelompok-kelompok sanggar seni yang menawarkan atraksi berupa nyanyian dan juga alat music lokal. Kelompokkelompok yang merupakan sub dari kelompok sadar wisata tersebut bekerja sesuai dengan mekanisme masing-masing dalam pengelolaan desa wisata tersebut.

3. Pergerakan

Monitoring terhadap semua sumber daya yang ada didalam organisasi agar bekerja dengan efektif dan efisien sehingga bisa mencapai tujuan. Pengelolaan Desa Wisata Waturaka dilakukan oleh masyarakat lokal sebagai subjek dan objek dari daya tarik wisata yang dimiliki. Monitoring tentu salah satunya dilakukan oleh kelompok sadar wisata sendiri dan selain itu dibantu oleh pihak pemerintah dan lembaga swadaya masyarakat Swisscontact untuk memberikan suksesor terhadap Desa Wisata Waturaka. Monitoring ini dilakukan untuk menginvestigasi semua aktivitas yang dikemas dalam pariwisata untuk memberikan hasil yang efektif dan efisien.

\section{Pengawasan}

Determinasi terhadap standar sehingga memberi penilaian terhadap proses yang berlangsung dari implementasi tersebut untuk memberikan perbaikan-perbaikan bila tidak sesuai dengan standar. Pengawasan dalam pengelolaan Desa Wisata Waturaka dilakukan oleh pemerintah dan juga lembaga swadaya masyarakat yang bernama Swisscontact untuk memberikan pelatihan terhadap masyarakat lokal dalam berinovasi untuk mengelolaah desa wisata tersebut.

\section{Metode penelitian}

Penelitian di Desa Wisata Waturaka, Kecamatan Kelimutu, Kabupaten Ende meninjau elemen produk pariwisata dan partisipasi masyarakat lokal didalam mengelola kepariwisataan. Ruang lingkup kajian meliputi: Komponen produk pariwisata meliputi: atraksi wisata, aksessibilitas, fasilitas wisata, dan institusi serta partisipasi masyarakat terdiri dari tahap perencanaan, pelaksaan program, pembagian hasil dan evaluasi. Akses metodelogi dalam penelitian ini yakni metodelogi kualitatif (data direduksi, disajikan lalu ditarik kesimpulan). Jenis data yakni data kualitatif serta kuantitatif. Teknik penentuan informan merujuk pada (Bungin 2007) yaitu orang yang dianggap menguasai topik permasalahan yang sedang dikaji. Informan dalam penelitian ini terdiri dari: Ketua kelompok sadar wisata Waturaka, masyarakat lokal Waturaka, lembaga swadaya masyarakat (Swisscontact) dan pemerintah setempat.

Pengumpulan data dilakukan dengan observasi dan wawancara (Suryawan, dkk., 2017), dan studi pustaka (Bungin, 2007). Observasi untuk mengetahui kondisi exisiting Desa Wisata Waturaka, wawancara dilakukan untuk mengetahui tentang komponen produk pariwisata dan partisipasi. Studi pustaka dilakukan untuk memahami kajian-kajian sebelumnya yang relevan.

\section{Hasil dan Pembahasan}

\subsection{Komponen produk pariwisata di Desa Wisata waturaka a. Atraksi}

Atraksi merupakan elemen vital dalam menarik wisatawan atau dengan kata lain atraksi adalah elemen primer dari suatu destinasi pariwisata. Potensi wisata adalah bentuk fundamental dari atraksi wisata yang eksistensinya sebagai modal dasar sumber daya pariwisata. Atraksi wisata yang terdapat di Desa Wisata Waturaka dapat dilampirkan dalam tabel 1 berikut:

\section{Tabel 1 Atraksi Wisata Waturaka}

\begin{tabular}{|l|l|l|}
\hline No & Atraksi alam & Atraksi budaya \\
\hline 1 & Air terjun murukeba & $\begin{array}{l}\text { Sanggar } \\
\text { budaya mutu } \\
\text { lo;o }\end{array}$ \\
\hline 2 & Air panas liasembe & $\begin{array}{l}\text { Sanggar } \\
\text { budaya } \\
\text { nuwanai }\end{array}$ \\
\hline 3 & Air panas kolorongo & $\begin{array}{l}\text { Situs budaya } \\
\text { kanga }\end{array}$ \\
\hline 4 & Uap panas mutu lo'o & Tubu musu \\
\hline 5 & Agrowisata & - \\
\hline
\end{tabular}

Sumber data: Hasil penelitian 2019 
Basis pengembangan Desa Wisata Waturaka adalah pengembangan community based tourism. Upaya pengembangan tersebut tentu memerlukan atraksi wisata yang kompetitif. Atraksi yang kompetitif adalah atraksi yang ditawarkan merupakan art by destination sehingga mempunyai nilai surplus di mata wisatawan untuk berkunjung. Desa wisata Waturaka menawarkan atraksi seperti pada (tabel 1.1.) yang ditawarkan berdasarkan local genius masyarakat.

\section{b. Aksesibilitas}

Aksesibilitas adalah elemen vital dalam aktivitas pariwisata. Eksistensi aksessibilitas sebagai link dalam sistem kepariwisataan. Aksessibilitas memberi arti terhadap perjalanan wisata. Motivasi wisatawan berkunjung ke suatu destinasi pariwisata harus didukung dengan ketersediaam aksessibilitas sehingga ada kemudahan untuk bepergian. Akses untuk menuju ke Desa Wisata Waturaka berupa akses fisik dan non fisik seperti pada tabel berikut:

Tabel 2. Aksesibilitas di Waturaka

\begin{tabular}{|l|l|l|}
\hline No & Akses fisik & $\begin{array}{l}\text { Akses non } \\
\text { fisik }\end{array}$ \\
\hline 1 & $\begin{array}{l}\text { Moda transportasi } \\
\text { darat }\end{array}$ & $\begin{array}{l}\text { Akses } \\
\text { melalui } \\
\text { website } \\
\text { Desa Wisata } \\
\text { Waturaka }\end{array}$ \\
\hline 2 & $\begin{array}{l}\text { Jalur trekking di Desa } \\
\text { Wisata Waturaka }\end{array}$ & Plung jalan \\
\hline
\end{tabular}

Sumber: Data penelitian 2019

\section{c. Amenitas}

Amenitas adalah kebutuhan primer wisatawan berupa sarana dan prasarana yang disediakan oleh pengelolah wisata untuk keperluan wisatawan selama berada di daerah yang menjadi tujuan wisata. Sarana serta prasarana yang terdapat di Desa Wisata Waturaka yakni akan dilampirkan dalam tabel berikut:

Tabel 3. Amenitas di Waturaka

\begin{tabular}{|l|l|l|}
\hline No & Tipe fasilitas pariwisata & Jumlah \\
\hline 1 & Pondok wisata & 15 \\
\hline 2 & Tempat parker & 15 \\
\hline
\end{tabular}

\begin{tabular}{|l|l|l|}
\hline 3 & Toilet umum & 2 \\
\hline 4 & Tempat sampah & 5 \\
\hline 5 & Ruang ganti & 1 \\
\hline
\end{tabular}

Sumber: Data penelitian 2019.

Kebutuhan primer yang harus dipenuhi oleh manajemen suatu destinasi pariwisata terhadap wisatawan dalam melakukan praktik wisata dalam konteks pariwisata berbasis masyarakat adalah fasilitas lokal sehingga wisatawan bisa berinteraksi langsung dan merasakan kehidupan baru di destinasi pariwisata tersebut. Fasilitas yang tersedia dengan konsep community based tourism adalah asset milik masyaraat lokal yang disediakan untuk wisatawan. Hal ini diharapkan investasi dari wisatawan selama berada di Desa Wisata Waturaka memberikan nilai ekonomi yang yang pro terhadap masyarakat di Desa Wisata Waturaka.

\section{d. Kelembagaan}

Kelembagaan adalah struktur politik atau manajemen kepariwisataan di suatu destinasi pariwisata. Destinasi pariwisata memerlukan kelembagaan yang mengelolah sehingga punya proyeksi yang jelas masa depan dari destinasi tersebut dan pengelolaanya harus pro terhadap masyrakat lokal. Desa Wisata Waturaka dikelolah oleh kelompok sadar wisata Waturaka dan didampingi oleh lembaga swadaya masyarakat (Swiscontact). Hal ini dikarenakan inovasi tentang pembangunan desa wisata Waturaka diinisiatifkan oleh masyarakat lokal sendiri dengan motif kekayaan asset sumber daya pariwisata yang dapat diajadikan produk wisata yang kompetitif.

\subsection{Partisipasi masyarakat dalam pengelolaan Desa Wisata Waturaka}

Partisipasi masyarakat lokal Desa Wisata Waturaka dalam pengembangan desa wisata berbasis masyarakat berdasarkan teori partisipasi masyarakat sehingga peneliti bisa mengkonstruksikan argumentasi untuk memberikan interpretasi dan justifikasi terhadap tahapan partisipasi masyarakat tersebut. Oleh karena itu, partisipasi masyarakat terdapat beberapa tahapan dalam uraian sebagai berikut:

1. Tahap perencanaan (Participation in decision making) 
Konstruksi argumentasi yang dibangun dalam fase ini adalah keterlibatan masyarakat desa wisata waturaka dalam rangka mengidentifikasi masalah untuk menghasilkna konsep pengembangan berbasis masyarakat, formulasi tujuan dan pengambilan keputusan. Berdasarkan penelitian yang dilakukan menunjukan bahwa masyarakt terlibat langsung melalui kelompok-kelompok kecil yang terdapat di desa wisata tersebut seperti: kelompok agrowisata yang mengemas atraksi yang berbasis alam dan kelompok sanggar seni. Keterlibatan masyarakat tersebut menimbulkan rasa optimisme msayarakat lokal lainya yang bisa berpartisipasi dalam konteks share holders untuk berlangsung aktivitas pariwisata. Oleh karena itu, dapat disimpulkan bahwa partisipasi masyarakat lokal dalam fase ini menghasilkan citizen power.

2. Tahap pelaksanaan program (Participation in implementation)

Argumentasi yang dibangun dalam fase partisipasi ini adalah ketika masyarakat lokal desa wisata Waturaka memutuskan consensus pembangunan pariwisata berbasis masyarakat melalui aksi-aksi konkret untuk mendorong pembangunan pariwisata berbasis masyarakat tersebut seperti: membentuk kelompok agrowisata untuk mengembangkan usaha pertanian yang bisa menghasilkan multiflier effect (sebagai atraksi wisata). Hal ini juga sebagai bentuk lain dari upaya konservasi pembangunan berkelanjutan dalam konteks community based tourism. Selain itu, terdapat juga kelompok sanggar seni untuk menyiapkan atraksi budaya berupa: tari-tarian lokal, tenun ikat, lagu-lagu masyarakat serta teknik menenun kain tradisional. Aksi konrekt lain yang dilakukan masyarakat lokal adalah pengembangan sarana dan prasarana wisata dengan tujuan untuk memberikan kenyamanan bagi wisatawan.

3. Tahapan pembagian hasil (participation in material incentives)

Argumentasi yang dibangun adalah hasil yang diterima oleh masyarakat lokal dalam partisipasi pembangunan pariwisata berbasis masyarakat seperti: membagi secara adil dan merata terhadap setiap kelompok yang terlibat dalam atraksi-atraksi wisata tersebut.
4. Tahap evaluasi (participation in evaluation)

Argumentasi yang dibangun dalam fase ini adalah proses justifikasi terhadap pengelolaan Desa Wisata Waturaka ditinjau dari berbagai dimensi seiring dengan dinamika kepariwisataan yang terjadi di desa wisata tersebut antara lain: pengembangan formulasi atraksi wisata baik alam dan budaya. Pengembangan tersebut dilihat dari aspek fisik atraksi yang disiapkan seperti rejuvinasi fasilitas di setiap daya tarik wisata agar bisa memenuhi kebutuhan wisatawan seiring dengan kuantitas kunjungan wisatawan yang masif dan pengemasan atraksi budaya yang progresif. Selain itu, evaluasi juga dilakukan terhadap aspek pelayanan yang diberikan oleh masyarakat kepada wisatawan. Hal ini terkait dengan program pemberdayaan masyarakat yang dilakukan oleh lembaga swadaya masyarakat dan pemerintah untuk terus meningkatkan human capital management lokal.

Berdasarkan fakta dilapangan menunjukan bahwa keikutsertaan masyarakat dalam konteks "share holders" belum sebagus keikutsertaannya sebagai "stakeholders". Desa Wisata Waturaka masih kurang agresif dalam menarik benefit dari wisatawan padahal realitas implementasi community based tourism menempatkan desa wisata waturaka berada pada uratan terbaik alam nomor 1 versi kementerian desa 2017.

Tampak Perlu adanya kesadaran masyarakat terkait kepariwisataan yang ada sehingga bisa mengambil manfaat ekonomi dari aktivitas wisata yang dilakukan tidak hanya dalam pengertian partisipasi aktif sebagai hakikat membangun sebuah desa wisata tetapi juga bisa pasif dalam mengambil keuntungan ekonomi dalam konteks shareholders.

Desa WIsata Waturaka perlu diberi label "ekowisata" dalam pengelolaan karena komponen produk wista yang ditawarkan adalah ciri khas dari desa wisata tersebut sehingga mempunyai nilai surplus tersendiri dalam konteks pengembangan pariwisata era postmodern (suistainable tourism).

\section{Simpulan dan Saran \\ 5.1 Simpulan}

Berdasarkan

substansi dari pembahasan diatas maka dapa disimpulkan Desa Wisata Waturaka berbasis masyarakat memiliki keterlibatan dari masyarakat lokal 
yang signifikan dalam pengelolaan komponen produk pariwisata yang dimiliki baik berupa produk wisata alam dan budaya. Komponen produk yang dikelolah adalah asset pariwisata yang dimiliki oleh Desa Wisata Waturaka. Pengelolaan tersebut melibatkan partisipasi masyarakat yang aktif. Hal tersebut dapat dilihat dari tingkatan partisipasi masyarakat lokal Waturaka dalam aspek pengelolaanya bahwa partisipasi masyarakat lokal berada dalam kadar partisipasi yang paling tinggi (citizen power) dalam pengelolaan Desa WIsata yang merujuk pada kriteria sebuah Desa Wisata.

\section{Daftar Pusataka}

Arnstein, S. R. (1996). Sebuah tangga partisipasi masyarakat. Jurnal asosiasi perencanaan Amerika, 35(4), 216224.

Bhattacharyya, J. (2004). Menteorikan pembangunan masyarakat. Jurnal pembangunan masyarakat, 34(2), 534

Blackstock, K. (2005). Sebuah tinjauan kritis tentang pariwisata berbasis masyarakat. Jurnal pengembangan masyarakat, 40(1), 39-49

Bungin, Burhan (2007) metodelogi penelitiian kualitatif.

Cooke, B., \& Kothari, U. (Eds.). (2001). Partisipasi: Tirani baru? New York, NY: Zed Books.

Cornwall, A. (2008). Partisipasi yang tidak dikemas. Model, makna dan praktik. Jurnal pengembangan masyarakat (3), 269-283.

Cooper et. al. 1993. Prinsp pariwista dan praktik .England : Longman Group Limited.

Goodwin, H., \& Santilli, R. (2009). Pariwisata berbasis masyarakat: sebuah kesuksesan. ICRT Occasional Paper, 11(1), 1-37.

Gunawan 2015. Metodelogi penelitian kualitatif.

Hausler, N., Strasdas, W. 2003. Latihan tahunan terhadap pariwisata berbasis masyarakat Zschortau: Inwent.

Mahagangga, I Gusti Agung Oka. Kelompok Sadar Wisata (Pokdarwis) dan Desa
Wisata. 2018. Presentasi Pengabdian

Kepada Masyarakat Prodi S3

Pariwisata Universitas Udayana, di

Desa Batuan, Kecamatan Sukawati,

Kabupaten Gianyar, Provinsi Bali, 31

Agustus $2018 . \quad$ DOI:

10.13140/RG.2.2.28167.01443

Moleong, Lexy. 2005. Metode Penelitian

Kualitatif. Bandung: PT. Remaja Rosdakarya.

Tasci, A. D. S., Semrad, K. J. \& Yilmaz, S. S. (2013). Pariwisata berbasis masyarakat dalam menemukan keseimbangan konteks COMCEC: Mengatur arah menuju masa depan COMCEC Coordination Office.

Terry, George Robert, and Stephen G. Franklin. Prinsip managemen. RD Irwin, 1968.

Suryawan, Ida Bagus dan Mahagangga, I Gusti Agung Oka. 2017. Penelitian Lapangan 1. Denpasar: Cakra Media Press dan Fakultas Pariwisata Universitas Udayana.

Windu, Nuryanti. 1993. konsep Perspektif dan tantangan, Yogyakarta: Gadjah Mada University Press. 